\title{
Sistem Pendukung Keputusan Pemilihan Lokasi TPA Sampah Menggunakan Metode Min_Max Inference Fuzzy
}

\author{
Ni Kadek Ariasih, I Putu Agung Bayupati, dan I Ketut Gede Darma Putra
}

\begin{abstract}
Abstrak- Disadari bahwa pemilihan lokasi Tempat Pambuangan Akhir (TPA) sampah sangatlah rumit mengingat banyaknya faktor yang perlu dipertimbangkan. Oleh karena itu diperlukan kriteria yang dapat digunakan untuk menentukan lokasi sampah yang layak dan memenuhi persyaratan. Adapun persyaratan tersebut dikukuhkan dalam Standar Nasional Indonesia (SNI) 03-3241-1994 yaitu tentang tata cara pemilihan lokasi TPA. Dalam penelitian ini disusun berdasarkan tahapan regional, dimana tahapan untuk menghasilkan peta yang berisi daerah dalam wilayah perencanan yang terbagi menjadi beberapa zona kelayakan. Dengan menggunakan metode MinMax Inference Fuzzy memudahkan dalam melakukan analisis data untuk menghasilkan keputusan layak, cukup layak dan Tidak layak suatu lokasi yang dipilih.
\end{abstract}

Index Terms — TPA, Min-Max Inference Fuzzy

\section{PENDAHULUAN}

L OKASI Tempat Pembuangan Akhir (TPA) merupakan lokasi pembuangan akhir sampah yang akan menerima segala resiko akibat pola pembuangan sampah terutama yang berkaitan dengan kemungkinan terjadinya pencemaran ke badan air maupun air tanah, pencemaran udara oleh gas dan efek rumah kaca serta berkembang biaknya vektor penyakit seperti lalat [1]. Permasalahannya yang akan terjadi jika TPA mengalami overload sampah, maka tidak dipungkuri masa layanan TPA sampah tersebut akan ditutup. Sehingga diperlukan suatu cara yaitu pemilihan lokasi TPA yang layak dan memenuhi standarisasi.

Proses pemilihan Lokasi TPA idealnya melalui suatu tahapan penyaringan. Di Negara industri penyaringan tersebut paling tidak terdiri dari 3 tahapan, yaitu tahap awal atau regional, tahap individu atau penyisihan, dan tahap final atau penetapan. Dari tiga tahapan tersebut yang digunakan dalam penelitian ini adalah tahapan awal atau regional. Tahapan atau kriteria regional ini diatur dalam Standar Nasioanal Indonesia (SNI) 03-3241-1994 yaitu tentang Tata Cara Pemilihan Lokasi TPA[1][2].

Ni Kadek Ariasih adalah Magister Teknik Elektro, Manajemen Sistem Informasi dan Komputer Universitas Udayana (e-mail: adek12150927@yahoo.co.id).

I Putu Agung Bayupati adalah Program Studi Teknologi Informasi Fakultas Teknik Universitas Udayana (e-mail: bayuhelix @yahoo.com).

I Ketut Gede Darma Putra adalah dengan Program Studi Teknologi Informasi Fakultas Teknik Universitas Udayana (e-mail: ikgdarmaputra@gmail.com).
Adapun parameter yang sering digunakan dalam penyaringan awal atau tahapan regional ini adalah Hidrogeologi, Hidrologi, topografi, ketersediaan air tanah, tata guna lahan, kondisi banjir, dan aspek-aspek yang lain. Sedangkan Parameter yang akan diujikan dalam penelitian ini adalah ditinjau dari aspek Geologi yaitu bukan daerah rawan gempa bumi, Hidrogeologi yaitu bukan daerah dengan debit sumur kuang dari 51/dt, Topografi yaitu kemiringan zona untuk lokasi TPA harus kurang dari 20\%, dan tata guna lahan yaitu tidak boleh berada pada daerah lindung dan dalam jarak 300 meter dari landasan terbang. Untuk menganalisis data melalui parameter tersebut diperlukan suatu metode agar menghasilkan suatu keputusan kelayakan dalam pemilihan lokasi TPA.

Dari penelitian sebelumnya tentang pemilihan lokasi TPA, ada beberapa metode yang digunakan seperti menghasilkan lokasi TPA berdasarkan klasifikasi daerah yang cocok dalam rentang antara 0 sampai 255 skala byte dengan menggunakan metode fuzzy logic dan Analytical Hierarchy Process (AHP) untuk menimbang informasi layer. Adapun parameter yang gunakan adalah topografi, tanah, permukaan air, ekosistem yang sensitif, penggunaan lahan dan peta geologi [3]. Penelitian [4], menggunakan tujuh belas faktor terpilih sebagai kriteria atau sub-kriteria yang diakui sebagai yang paling penting, dibagi menjadi geo-alam, faktor lingkungan, sosial dan tekno-ekonomi, dan dievaluasi oleh para ahli dari berbagai bidang menggunakan ekstensi AHP di Arc GIS. Berdasarkan temuan tersebut, lima lokasi dekat dengan dua aglomerasi perkotaan besar yang diusulkan sebagai lokasi yang mungkin untuk TPA regional di Srem. Sedangkan pada penelitian [5] menjelaskan tentang GIS( dan Fuzzy Multi Kriteria Analisis Keputusan (FMCDA) yang terintegrasi untuk memecahkan masalah pemilihan lokasi TPA dan mengembangkan ranking dari daerah TPA potensial berdasarkan berbagai kriteria.

Dengan demikian maka dalam penelitian ini diarancang dan dibangun suatu sistem pendukung keputusan pemilihan lokasi TPA sampah dengan menggunakan metode Min-Max Inference Fuzzy. Studi ini melakukan penerapan Min-Max Inference Fuzzy yang merupakan salah satu teknik inferensi fuzzy yang terdapat dalam komputasi pada metode fuzzy. Kelebihan dari metode ini dibandingkan dengan metode yang digunakan oleh penelitian sebelumnya yaitu karena penalaran metode Min-Max lebih menyerupai pola pikir manusia karena 
fungsi implikasi antara antecedent dan consequent sama-sama dalam himpunan fuzzy. Metode ini digunakan untuk menganalisis data untuk menghasilkan keputusan apakah wilayah yang terpilih tersebut layak, cukup layak atau tidak layak untuk dijadikan lokasi TPA sampah yang baru sesuai dengan kriteria regional.

\section{TINJAUAN PUSTAKA}

\section{A. Tata Cara Pemilihan Lokasi TPA Sampah}

TPA merupakan tempat dimana sampah diisolasi secara aman agar tidak menimbulkan gangguan terhadap lingkungan sekitarnya. Karenanya diperlukan penyediaan fasilitas dan perlakuan yang benar agar keamanan tersebut dapat dicapai dengan baik[3].

Mengingat besarnya potensi dalam menimbulkan gangguan terhadap lingkungan maka pemilihan lokasi TPA harus dilakukan dengan seksama dan hati-hati.Hal ini ditunjukkan dengan sangat rincinya persyaratan lokasi TPA seperti tercantum dalam SNI No 03-3241-1994 tentang Tata Cara Pemilihan Lokasi Tempat Pembuangan Akhir Sampah.Adapun persyaratan lokasi TPA diantaranya dalam kriteria regional dicantumkan[2]:

1. Bukan daerah rawan geologi (daerah patahan, daerah rawan longsor, rawan gempa, dll)

2. Bukan daerah rawan hidrogeologis yaitu daerah dengan kondisi kedalaman air tanah kurang dari 3 meter, jenis tanah mudah meresapkan air, dekat dengan sumber air (dalam hal tidak terpenuhi harus dilakukan masukan teknologi)

3. Bukan daerah rawan topografis (kemiringan lahan lebih dari 20\%)

4. Bukan daerah rawan terhadap kegiatan penerbangan di Bandara (jarak minimal 1,5 - $3 \mathrm{~km}$ )

5. Bukan daerah/kawasan yang dilindungi

\section{B. Min-Max Inference Fuzzy}

Metode Min-Max sering juga dikenal dengan nama Metode Mamdani. Metode ini diperkenalkan oleh Ebrahim Mamdani pada tahun 1975. Untuk mendapatkan output, diperlukan 4 tahapan: (1) Pembentukan himpunan fuzzy; (2) Aplikasi fungsi implikasi (aturan); (3) Komposisi aturan; (4) Penegasan (deffuzy).

1. Pembentukan himpunan fuzzy

Pada Metode Min-Max, baik variabel input maupun variabel output dibagi menjadi satu atau lebih himpunan fuzzy.

2. Aplikasi fungsi implikasi pada Min-Max, fungsi implikasi yang digunakan adalah Min.

3. Komposisi Aturan

Tidak seperti penalaran monoton, apabila sistem terdiridari beberapa aturan, maka inferensi diperoleh dari kumpulan dan korelasi antar aturan. Ada 3 metode yang digunakan dalam melakukan inferensi sistem fuzzy, yaitu: max, additive dan probabilistik OR (probor).

\section{a. Metode Max (Maximum)}

Pada metode ini, solusi himpunan fuzzy diperoleh dengan cara mengambil nilai maksimum aturan, kemudian menggunakannya untuk memodifikasi daerah fuzzy, dan mengaplikasikannya ke output dengan menggunakan operator OR (union). Jika semua proposisi telah dievaluasi, maka output akan berisi suatu himpunan fuzzy yang merefleksikan konstribusi dari tiap-tiap proposisi. Secara umum dapat dituliskan :

$$
\mu \mathrm{sf}[\mathrm{xi}]<--\max (\mu \mathrm{sf}[\mathrm{xi}], \mu \mathrm{kf}[\mathrm{xi}]
$$

dengan:

$\mu \mathrm{sf}[\mathrm{xi}]=$ nilai keanggotaan solusi fuzzy sampai aturan ke-i;

$\mu \mathrm{kf}[\mathrm{xi}]=$ nilai keanggotaan konsekuen fuzzy aturan ke-i;

Apabila digunakan fungsi implikasi MIN, maka metode komposisi ini sering disebut dengan nama MAX-MIN atau MIN-MAX atau MAMDANI.

b. Metode Additive (Sum)

Pada metode ini, solusi himpunan fuzzy diperoleh dengan cara melakukan bounded-sum terhadap semua output daerah fuzzy. Secara umum dapat dituliskan sebagai berikut :

$$
\mu \mathrm{sf}[\mathrm{xi}]<--\min (1, \mu \mathrm{sf}[\mathrm{xi}]+\mu \mathrm{kf}[\mathrm{xi}])
$$

dengan:

$\mu \mathrm{sf}[\mathrm{xi}]=$ nilai keanggotaan solusi fuzzy sampai aturan ke-i;

$\mu \mathrm{kf}[\mathrm{xi}]=$ nilai keanggotaan konsekuen fuzzy aturan ke-i;

c. Metode Probabilistik OR (Probor)

Pada metode ini, solusi himpunan fuzzy diperoleh dengan cara melakukan product terhadap semua output daerah fuzzy. Secara umum dapat dituliskan sebagai berikut :

$\mu \mathrm{sf}[\mathrm{xi}]<--\left(\mu \mathrm{sf}[\mathrm{xi}]+\mu \mathrm{kf}[\mathrm{xi}]-\left(\mu \mathrm{sf}[\mathrm{xi}]^{*} \mu \mathrm{kf}[\mathrm{xi}]\right)\right.$

dengan:

$\mu \mathrm{sf}[\mathrm{xi}]=$ nilai keanggotaan solusi fuzzy sampai aturan ke-i;

$\mu \mathrm{kf}[\mathrm{xi}]=$ nilai keanggotaan konsekuen fuzzy aturan ke-i;

4. Penegasan (defuzzy)

Input dari proses defuzzifikasi adalah suatu himpunan fuzzy yang diperoleh dari komposisi aturan-aturan fuzzy, sedangkan output yang dihasilkan merupakan suatu bilangan pada domain himpunan fuzzy tersebut. Sehingga jika diberikan suatu himpunan fuzzy dalam range tertentu, maka harus dapat diambil suatu nilai crsip tertentu sebagai outputnya.

Ada beberapa metode defuzzifikasi pada komposisi aturan MAMDANI, antara lain:

a. Metode Centroid (Composite Moment)

Pada metode ini, solusi crisp diperoleh dengan cara mengambil titik pusat $\left(\mathrm{z}^{*}\right)$ daerah fuzzy.

b. Metode Bisektor

Pada metode ini, solusi crisp diperoleh dengan cara mengambil nilai pada domain fuzzy yang memiliki nilai keanggotaan separo dari jumlah total nilai keanggotaan pada daerah fuzzy. 


\section{c. Metode Mean of Maximum (MOM)}

Pada metode ini, solusi crisp diperoleh dengan cara mengambil nilai rata-rata domain yang memiliki nilai keanggotaan maksimum.

d. Metode Largest of Maximum (LOM)

Pada metode ini, solusi crisp diperoleh dengan cara mengambil nilai terbesar dari domain yang memiliki nilai keanggotaan maksimum.

e. Metode Smallest of Maximum (SOM)

Pada metode ini, solusi crisp diperoleh dengan cara mengambil nilai terkecil dari domain yang memiliki nilai keanggotaan maksimum.

\section{Metodelogi Penelitian}

Penelitian ini menggunakan beberapa fitur atau peta dalam menentukan lokasi TPA di Kabupaten Klungkung dengan skala 1:25.000 yang diterbitkan oleh BAPPEDA Kabupaten Klungkung. Adapun fitur tersebut antara lain:

- Pertama yaitu fitur Administrasi Kabupaten Klungkung yang berisi tentang batas kabupaten dan kecamatan.

- Kedua, fitur Hidrogeologi menggambarkan tentang wilayah yang memiliki kandungan air tanah atau debit sumur seperti debit sumur kurang dari $5 \mathrm{l} / \mathrm{dt}$, sama dengan $5 \mathrm{l} / \mathrm{dt}$, dan sama dengan $10 \mathrm{l} / \mathrm{dt}$.

- Ketiga, fitur Tata Guna Lahan memberikan informasi tenang pemukiman, gedung, sawah tadah hujan, tanah berbatu, sawah irigasi, rawa,hutan rawa, tanah lading, kebun, rumput, dan belukar.

- Keempat, fitur Geologi menggambarkan area rawan bencana gempa yaitu kawasan rawan sangat tingi, kawasan rawan tinggi, kawasan rawan menengah, dan kawasan rawan rendah.

- Dan terakhir Kelima, fitur topografi yaitu menggambarkan area yang memiliki kemiringan lahan antara lain kemiringan lahan lebih dari $40 \%$, antara $0-3 \%$, antara $3-8 \%$, antara $8-15 \%$, antara $15-25 \%$ dan antara $25-$ $40 \%$.

Hal pertama yang dilakukan dengan menggunakan teknik GIS yaitu meng-overlay fitur - fitur tersebut, sehingga menghasilkan satu fitur. Kemudian fitur tersebut dianalisis menggunakan metode Min-Max Inference Fuzzy, untuk menghasilkan keputusan tentang kelayakan lokasi TPA Sampah baru sesuai dengan tahapan regioanal berdasarkan acuan dari SNI 03-3241-1994 yaitu tentang Tata Cara Pemilihan Lokasi TPA.

\section{HASIL DAN PEMBAHASAN}

Pada proses pemilihan lokasi TPA sampah pada penelitian ini, yaitu dengan cara melakukan uji coba lokasi TPA baru yang terletak di wilayah Desa Gunaksa Kecamatan Dawan Kabupaten Klungkung. Adapun contoh dari hasil masukan point peta di sistem, yaitu : dengan cara menambahkan sebuah titik lokasi mana yang diinginkan oleh pengguna seperti yang terlihat pada Gambar 1. Proses selanjutnya sistem akan otomatis memberikan hasil analisis dan keputusan yang dapat diberikan pada lokasi TPA baru yang dipilih seperti yang terlihat pada Gambar 2

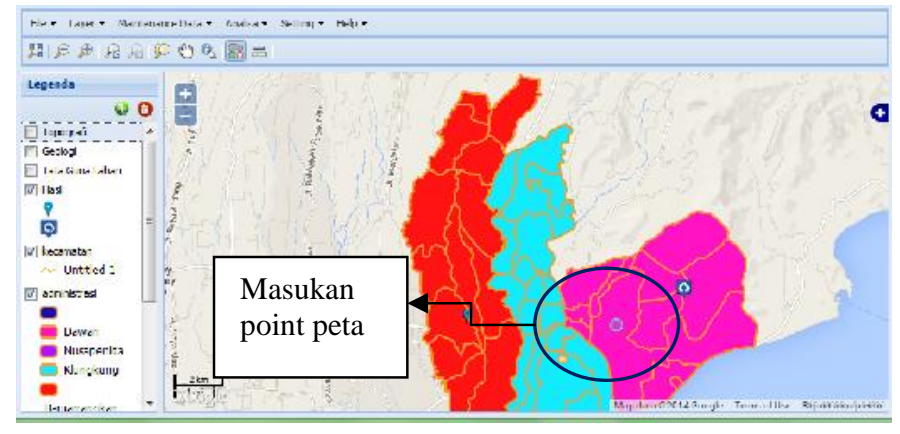

Gambar 2. Add Point Feature

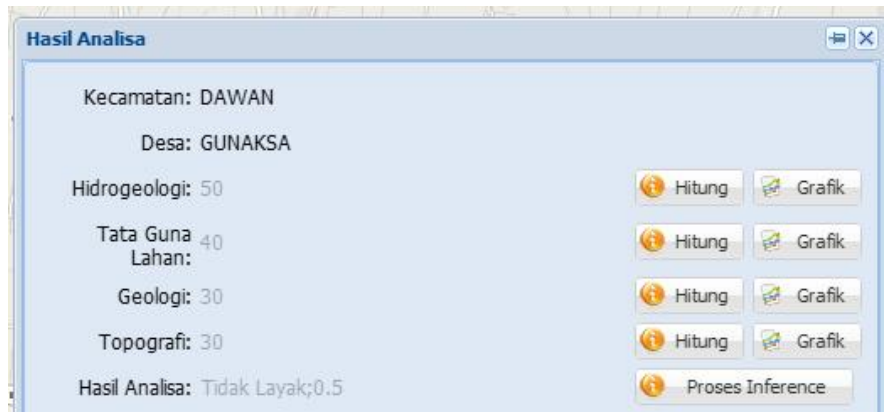

Gambar 3. Hasil akhir analisa

Pada Gambar 3 merupakan contoh rule yang menunjukan proses perhitungan fuzzy set dengan menerapkan Min-Max Inference Fuzzy, merupakan bagian dari proses inferensi yang melakukan penalaran menggunakan fuzzy input dan fuzzy rules yang telah ditentukan sehingga menghasilkan fuzzy output. Fungsi implikasi yang digunakan dalam proses ini adalah fungsi MIN, yaitu dengan mengambil tingkat keanggotaan yang minimum dari variabel input sebagai outputnya. Berdasarkan aturan-aturan yang sesuai dengan kondisi tersebut maka diperoleh 36 rule dengan menghasilkan keputusan atau DSS adalah "Tidak Layak"

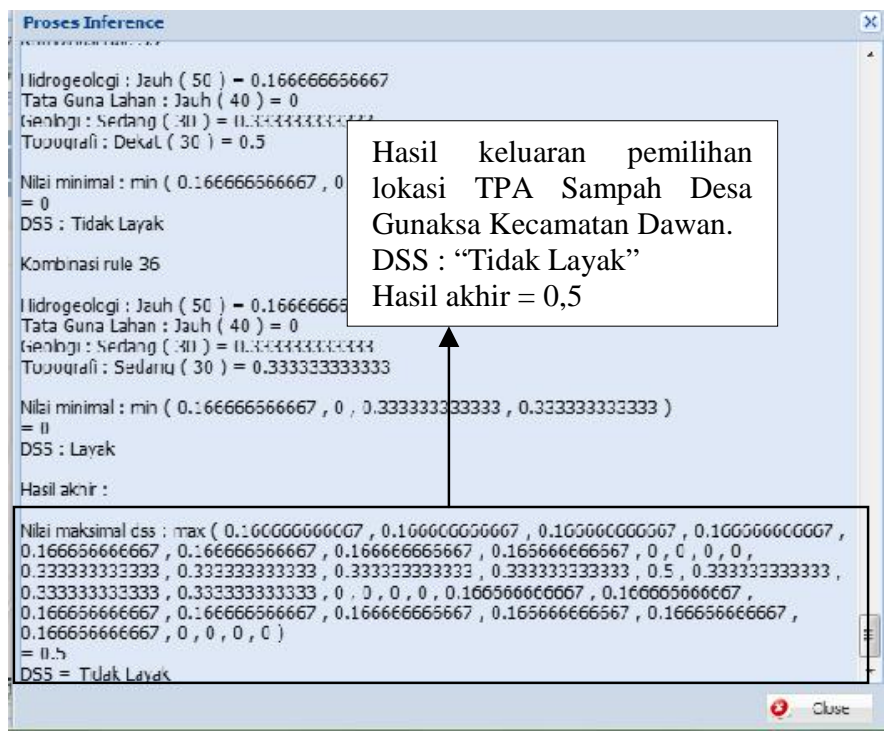

Gambar 3. Add Point Feature 
Berdasarkan data yang diperoleh pada gambar 4 maka salah satu contoh rule pada aturan predikat untuk penilain semua variabel yang ada misalnya terdapat pada rule 1 yaitu :

\section{Kombinasi Rule 1 :}

[R1] IF Hidrogeologi adalah Dekat AND Tata Guna Lahan adalah Dekat AND Geologi adalah Dekat AND Topografi adalah Sedang THEN DSS adalah Tidak Layak. Mengacu pada fungsi keanggotaan kelompok masing-masing diperoleh nilai keanggotaan masing-masing data yaitu :

$$
\begin{aligned}
& \alpha \text {-predikat }_{1}=\mu_{\text {Hidrogeologi }} \text { Dekat } \curvearrowright \mu_{\text {TataGunaLahan }} \\
& \text { Dekat }{ }^{\wedge} \mu_{\text {Geologi }} \text { Dekat }{ }^{\wedge} \mu_{\text {Topografi }} \\
& \text { Sedang } \\
& =\min \left(\mu_{\text {Hidrogeologi }} \text { Dekat }[50]\right. \text {, } \\
& \mu_{\text {TataGunaLahan }} \text { Deka[40], } \\
& \mu_{\text {Geologi }} \text { Dekat[30], } \mu_{\text {Topografi }} \\
& \text { Dekat[30]) } \\
& =\operatorname{Min}(0,167 ; 0,333 ; 0,5 ; 0,5) \\
& =0,167 \\
& \text { DSS }=\text { Tidak Layak }
\end{aligned}
$$

Proses selanjutnya komposisi aturan merupakan kesimpulan secara keseluruhan dengan mengambil tingkat keanggotaan maksimum dari tiap konsekuen aplikasi fungsi implikasi dan menggabungkan dari semua kesimpulan masing-masing aturan. Fungsi yang digunakan untuk komposisi aturan pada penelitian ini dengan menggunakan fungsi MAX, sehingga diperoleh daerah solusi fuzzy sebagai berikut:

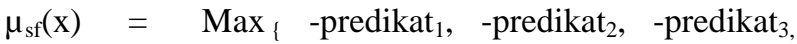

$$
\begin{aligned}
& \alpha \text {-predikat4, } \alpha \text {-predikat5, } \alpha \text {-predikat6, } \\
& \alpha \text {-predikat7, } \alpha \text {-predikat8, } \alpha \text {-predikat9, } \\
& \alpha \text {-predikat10, } \alpha \text {-predikat11, } \alpha \text {-predikat12, } \\
& \alpha \text {-predikat14, } \alpha \text {-predikat15, } \alpha \text {-predikat16, } \\
& \alpha \text {-predikat17, } \alpha \text {-predikat18, } \alpha \text {-predikat19, } \\
& \alpha \text {-predikat20, } \alpha \text {-predikat } 21, \alpha \text {-predikat22, } \\
& \alpha \text {-predikat23, } \alpha \text {-predikat24, } \alpha \text {-predikat25, } \\
& \alpha \text {-predikat26, } \alpha \text {-predikat27, } \alpha \text {-predikat28, } \\
& \alpha \text {-predikat29, } \alpha \text {-predikat30, } \alpha \text {-predikat31, } \\
& \alpha \text {-predikat32, } \alpha \text {-predikat33, } \alpha \text {-predikat34, } \\
& \alpha \text {-predikat 35, } \alpha \text {-predikat } 36\} \\
& =\operatorname{Max}\{0,167 ; 0,167 ; 0,167 ; 0,167 ; 0,167 ; 0,167 \text {, } \\
& 0,167 ; 0,167 ; 0 ; 0 ; 0 ; 0 ; 0,333 ; 0,333 ; 0,333 ; 0,5 \text {; } \\
& 0,333 ; 0,333 ; 0,333 ; 0,333 ; 0 ; 0 ; 0 ; 0,167 ; 0,167 \text {; } \\
& 0,167 ; 0,167 ; 0,167 ; 0,167 ; 0,167 ; 0,167 ; 0 ; 0 ; 0 ; 0\} \\
& =0,5
\end{aligned}
$$

Maka hasil yang diperoleh dari sistem untuk uji coba lokasi TPA Sampah baru yang terletak di Desa Gunaksa Kecamatan Dawan yang dipilih oleh pengguna sistem untuk menguji kelayakan lokasi. Dimana hasil Nilai DSS adalah 0,5 dan dengan hasil bahasa DSS-nya adalah Tidak Layak.

Pada gambar 5 menujukan hasil analisa dalam bentuk tabel sehingga sistem dapat melihat secara keseluruhan data hasil uji coba lokasi TPA sampah.

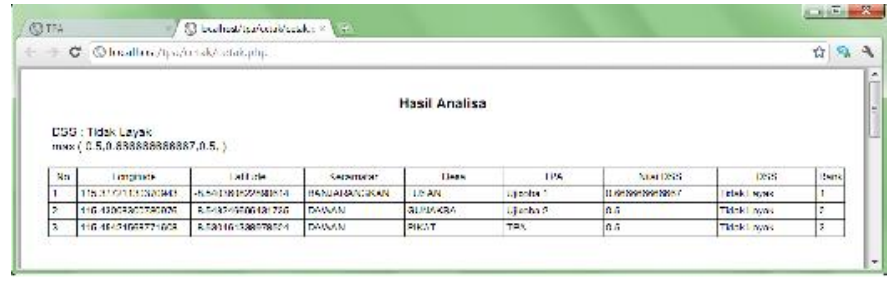

Gambar 5. Hasil akhir Keseluruhan dalam bentuk tabel

\section{KESIMPULAN}

Berdasarkan dari proses pengujian yang telah dilakukan, dapat disimpulkan bahwa sistem ini dapat memperoleh alternative keputusan kelayakan lokasi-lokasi TPA sampah sesuai dengan ketentuan teknis SNI No. 19-3241-1994 berdasarkan kriteria regional dan metode max-min inference fuzzy yang digunakan untuk melakukan analisis kelayakan lokasi dapat diterapkan pada sistem. Adapun Keputusan dari Desa Gunaksa Kecamatan Dawan menghasilkan nilai keputusan yaitu 0,5, maka sistem menghasilkan keputusan "Tidak Layak". Adapun kriteria yang dihasilkan dan jika dilihat melalui pengamatan secara langsung dan dengan di sistem yaitu desa Gunaksa kecamatan Dawan merupakan daerah ladang, secara hidrologogi memiliki kandungan air yang sangat tinggi dengan debit air 2lt/dt, dengan kemiringan tanah mencapai $15-25 \%$ dan dekat dengan daerah pemukiman

\section{DAFTAR PUSTAKA}

[1] J. Petts," Envoronmental Impact Assesment for Waste Treatment \& Disposal Facilities", 1996.

[2] ..............., SNI 19-3241-1994 tentang Tata Cara Pemilihan Lokasi Tempat Pembuangan Akhir Sampah". Dinas Pekerjaan Umum.

[3] ..............," Undang-undang Republik Indonesia Nomor 18 Tahun 2008 tentang Pengelolaan Sampah", 2008

[4] A. Afzali, J. M. V. Samani,M. Rashid, "Municipal Landfill Site Selection For Isfahan City By Use Of Fuzzy Logic And Analytic Hierarchy Process", J. Environ. Health. Sci. Eng., Vol. 8, No. 3, 2011, pp. 273-284.

[5] T. Zelenovic Vasiljevic, Z. Srdjevic, R. Bajc`etic', M. V. Miloradov, “ GIS and the Analytic Hierarchy Process for Regional Landfill Site Selection in Transitional Countries: A Case Study From Serbia, Environmental Management", 49, 2011, hal. 445-458.

[6] V. Akbari, M.A. Rajabi, S.H. Chavoshi dan R. Shams, "Landfill Site Selection by Combining GIS and Fuzzy Multi Criteria Decision Analysis, Case Study: Bandar Abbas", Iran.Journal of Department of Surveying and Geomatics Engineering, University of Tehran, Iran, 2008

[7] S. Kusumadewi,"Aplikasi Logika Fuzzy Untuk Pendukung Keputusan", Graha Ilmu Yogyakarta, 2010

[8] T. J. Ross,"Fuzzy Logic With Engineering Application", Second Edition, University of New Mexico, USA. 